\title{
Types of Understanding Their Nature and Their Relation to Knowledge
}

\section{Journal Article}

\section{Author(s):}

Baumberger, Christoph

Publication date:

2014-02

Permanent link:

https://doi.org/10.3929/ethz-b-000091270

\section{Rights / license:}

In Copyright - Non-Commercial Use Permitted

\section{Originally published in:}

Conceptus 40(98), https://doi.org/10.1515/cpt-2014-0002 


\title{
Christoph Baumberger
}

\section{Types of understanding: Their nature and their relation to knowledge}

\begin{abstract}
What does it mean to understand something? I approach this question by comparing understanding with knowledge. Like knowledge, understanding comes, at least prima facia, in three varieties: propositional, interrogative and objectual. I argue that explanatory understanding (this being the most important form of interrogative understanding) and objectual understanding are not reducible to one another and are neither identical with, nor even a form of, the corresponding type of knowledge (nor any other type of knowledge). My discussion suggests that definitions of the concepts of explanatory and of objectual understanding must include a commitment condition, a grasping condition, an answering-the-facts condition, and an epistemically internal justification condition, but no further external anti-luck condition. On this basis I argue against reducing explanatory understanding to propositional understanding, and in favour of identifying propositional understanding with propositional knowledge.
\end{abstract}

Christoph Baumberger: ETH Zurich, Institute for Enviromental Decisions, Universitätstrasse 16, 8092 Zürich, Switzerland, E-Mail: christoph.baumberger@env.ethz.ch

Epistemology is usually conceived of as the theory of knowledge, concerned with the nature, sources and limits of knowledge. Knowledge is identified with propositional knowledge and analysed in terms of justified or reliably generated true belief, perhaps extended by a further condition designed to avoid Gettier counterexamples. However, epistemology's focus on propositional knowledge has recently been challenged. There is a growing insight that understanding, rather than propositional knowledge, is our main cognitive goal. Once we acknowledge the central role of understanding, authors have argued, we will be better able to accommodate science within epistemology (Elgin 1996; 2007), identify the intellectual virtues (Zagzebski 2001; Riggs 2003), avoid the value problem for knowledge (Kvanvig 2003; Pritchard 2010), and defend morality against the egoist (Hills 2010). These potential roles for the concept of understanding have been widely discussed, but few epistemologists have made serious efforts to deal with the nature of understanding. In this paper, I analyse what it means to understand something by comparing understanding with knowledge. 
There are two standard views regarding the relation between understanding and knowledge. Outside epistemology, particularly in the philosophy of science, the standard view is that understanding is a form of knowledge (Salmon 1993; Woodward 2003; Lipton 2004; Grimm 2006). Within epistemology, the standard view is that understanding is neither identical with nor a form of knowledge (Zagzebski 2001; Kvanvig 2003; Elgin 2007; Hills 2010; Pritchard 2010). This debate, however, has not always given due acknowledgement of the fact that, at least prima facia, both understanding and knowledge come in three varieties. While accepting that ordinary language is not always a reliable guide, we may appeal to it here as a means of classifying these varieties in terms of the grammatical form of the ascription: if the ascription of understanding or knowledge uses a "that" clause, it is propositional; if it uses a "wh-" clause, it is interrogative; and if it uses a noun phrase, it is objectual. Zagzebski (2001), for instance, leaves it unclear which type of understanding she is comparing with which type of knowledge; Kvanvig (2003) and Elgin (2007) contrast different types, notably objectual understanding and propositional knowledge; Grimm (2006), Pritchard (2010), Hills (2010) and most philosophers of science consider only certain types, notably explanatory understanding and knowledge (i.e. the most important form within the interrogative category).

Questions regarding the nature of understanding and its relation to knowledge must thus be answered with respect to different types of understanding and knowledge. I therefore proceed, first, by providing a division of understanding by delimiting and characterizing the uses of "understand" that are relevant for my project (Sect. 1). With respect to explanatory and objectual understanding, I then argue that these are not reducible to one another, and are neither identical with, nor even a form of, the corresponding type of knowledge - or indeed any of the other forms of knowledge (Sects. 2 and 3). My discussion reveals important characteristics of these two types of understanding, which suggest that definitions of the concepts of explanatory and of objectual understanding must include a "commitment" condition, a "grasping" condition, an "answering-the-facts" condition and an "epistemically internal justification" condition, but not a further "external anti-luck” condition (Sect. 4). Finally, I turn to propositional understanding and argue against reducing explanatory understanding to it, but in favour of identifying it with propositional knowledge (Sect. 5).

\section{The division of understanding}

The expressions "to understand" and "understanding" are used in a variety of ways. Let me begin by providing some examples; these fall into three groups, 
depending on the grammatical form of the attribution of understanding. In its verb form, we can give examples such as:

(1) You understand why the global mean temperature has increased.

(2) He understands what justice demands.

(3) They understand how the machine works.

(4) She understands global warming.

(5) You understand that the train leaves in an hour.

(6) I understand that you are angry with me.

In its noun form, we can give examples such as:

(7) My understanding was that you would get the job.

(8) They came to an understanding on when the final payment was to be made.

(9) Each of us has an understanding as well as a will and a sensibility.

In its adjectival form, we can give examples such as:

(10) She has very understanding parents.

Some usages are irrelevant to epistemology. For instance, I can say "I understand" to hedge an assertion or to moderate its force (Elgin 2007: 34). I might utter (6) when I have some reason to think that you are angry with me, but am not wholly convinced of the truth of the claim. In such a hedging use, "I understand" indicates a refraining from a full-blown claim to epistemic warrant. Hedging usages bear important connections to noun forms such as in (7), where speaking of someone's understanding of something being such-and-such is compatible with their being (largely) wrong. Alternatively, I might utter (6) when I know that you are angry with me and I try to remedy the situation by signalling that I can see some reason for your anger. In such a moderating use, "I understand" indicates my sympathetic awareness of your feelings and invites you to resolve your anger. Moderating usages are related to adjectival forms such as in (10), where "understanding" means "sympathetic". Furthermore, "understanding” can be used to express an informal agreement, as in (8). Hence we are left with the verb forms in (1) to (5) and the noun form in (9) as examples of epistemologically relevant usage.

Within the epistemologically relevant usages we can distinguish between usages referring to understanding as a faculty, as a process, and as the result of a process. In (9) “understanding” refers to a cognitive faculty in an inclusive sense consisting of various cognitive abilities. (1) to (5) can either be read as referring to 
the process of coming to understand by making use of cognitive abilities, or, perhaps more naturally, as referring to an understanding that is the result of such a process. In both readings, "to understand" is a verb of success. Unless the usage in question is a hedging usage, to say that someone understands something means that she understands it (more or less) correctly. In what follows, I use the term to imply cognitive success with regard to the result. This is the usage that is relevant for comparing understanding and knowledge, since "knowledge" does not refer to a faculty and is hardly used to refer to a process.

The object of understanding can either be some worldly item or a symbolic representation thereof. Understanding some fact, event or subject matter I call "factual understanding"; understanding a symbolic representation - such as a sentence, explanation, diagram or theory - I call "symbolic understanding". Factual and symbolic understanding have to be kept apart, since the symbolic representation which in the second case is the object of understanding is in the first case its vehicle; that is, the means by which one understands some object. One can understand a sentence, explanation, diagram or theory without committing oneself to it and regardless of whether it is true or accurate; but this does not hold for an understanding of what it represents. Understanding a subject matter by means of a theory, for instance, presupposes that one commits oneself to the theory and that it is broadly correct. That is why you can understand phlogiston theory, but you cannot understand combustion in terms of it. Symbolic understanding is a precondition for factual understanding whenever the latter is symbolically conveyed. Nonetheless, as an epistemologist I am primarily concerned with factual understanding. Symbolic and, more specifically, linguistic understanding are the subjects of semiotics and the philosophy of language, respectively.

In ascriptions of understanding in its verbal form, "to understand" is either followed by a "wh-" clause, a noun phrase or a "that" clause. The three grammatical forms of the ascriptions of understanding are usually taken to constitute three types of understanding. Ascriptions employing a "wh-" clause ascribe interrogative understanding, which includes, for example, understanding why, what and how, as in (1) to (3); ascriptions employing a noun phrase ascribe objectual understanding, as in (4); and ascriptions employing a "that" clause ascribe propositional understanding, as in (5) (cf. Grimm 2011: 84-8). In exactly the same manner, there is also interrogative, objectual and propositional knowledge. Moreover, in all verb form examples (1) to (5), we can substitute "under-

1 I prefer "symbolic understanding" to "semantic understanding" (Cooper 1994: 1-2) or "linguistic understanding" (Grimm 2011: 84), since it may concern syntactic and pragmatic aspects (such as syntactic ambiguity and illocutionary roles) as well as semantic ones, and non-verbal symbols (such as diagrams, graphs, maps and three-dimensional models) as well as verbal ones. 
stands" with "knows" without turning the sentences into manifest nonsense. However, this does not settle my question regarding the relations between the different types of understanding and knowledge, since it does not imply that the sentences do not change their meaning thereby; knowing a person, for instance, is not the same as understanding her.

The different grammatical forms of ascriptions of understanding do not directly deliver a useful typology of understanding. Too many "wh-" clauses can be substituted by a clause entailing another interrogative, or even by a noun phrase or a "that" clause. "You understand why the global mean temperature has increased", for instance, can be paraphrased as "You understand what the causes of global warming are", as well as "You understand the causes of global warming" or, perhaps, as "You understand that the global mean temperature has increased because... ." As a starting point for developing a more stable typology, for paradigmatic cases of each prima facie type, we may ask what the object and what the vehicle is. In paradigmatic cases of understanding-why - the only interrogative form I consider -, the vehicle is an explanation that answers the why-question and the object is a phenomenon like an event (e.g. rise of temperature); understanding-why, then, is explanatory understanding. In paradigmatic cases of objectual understanding, the vehicle is a more comprehensive body of information, such as a whole theory or account, and the object is a subject matter (e.g. global warming), a topic (e.g. justice) or a system (e.g. a machine). ${ }^{3}$ In the case of propositional understanding, the vehicle is a proposition, and the object is a fact (e.g. that the temperature has increased).

Since it is rare to talk of understanding that something is the case - and if we do, "understands" often has a hedging connotation that suggests an openness to correction - I first focus on explanatory and on objectual understanding, and subsequently draw some conclusions from my discussion regarding propositional understanding.

2 However, in objectual cases in which the object is a complete subject matter as in (4), "understands" seems more natural than "knows"; "She knows global warming", for instance, sounds slightly odd.

3 Ascriptions of objectual understanding that do not relate to a comprehensive body of information may arguably be interpreted as elliptical for the corresponding ascriptions of interrogative understanding. For instance, "She understands his action" can mean "She understands what kind of action he has performed" or "She understands why he did what he did", and so on. 


\section{Explanatory understanding}

Understanding is a form of knowledge if it implies knowledge; in order to be identical with knowledge it additionally needs to be implied by knowledge. I first argue that it is possible to know that and even why $\mathrm{p}$ without understanding why $\mathrm{p}$; hence, that explanatory understanding is equivalent neither to propositional knowledge nor to explanatory knowledge (Sect. 2.1). I then argue that it is possible to understand why $\mathrm{p}$ without knowing why $\mathrm{p}$; hence, that explanatory understanding is not even a form of knowledge (Sect. 2.2).

\subsection{Knowledge without understanding}

Obviously, you can know that $\mathrm{p}$ without understanding why $\mathrm{p}$. Suppose a climate scientist tells you that the global mean temperature has increased since the middle of the $20^{\text {th }}$ century. If he is right, and you have good reasons to believe in his reliability, you know that the global mean temperature has increased. But as long as you have no idea what the causes of global warming are, you do not understand why the global mean temperature has increased.

One might object that this only shows that you can know that $\mathrm{p}$ without knowing why $\mathrm{p}$, but not that you can know why $\mathrm{p}$ without understanding why $\mathrm{p}$. Most philosophers of science identify understanding with explanatory knowledge. According to Lipton, for instance, "[u]nderstanding is not some sort of super-knowledge, but simply more knowledge: knowledge of causes" (Lipton 2004: 30). However, if we slightly modify this testimony case, it shows that even knowing why p does not imply understanding why p (cf. Pritchard 2010: 81). Suppose your climate scientist explains to you that the global mean temperature has increased mainly due to increasing concentrations of greenhouse gases. If he is right, and you have good reason to believe him to be reliable, then you know why the global mean temperature has increased. But as long as you have no grasp of how increasing concentrations of greenhouse gases can cause global warming, and you only have testimonial evidence for the given explanation, you do not understand why the global mean temperature has increased.

This example suggests two ways in which explanatory understanding differs from explanatory knowledge. ${ }^{4}$ First, while explanatory knowledge involves a

4 Pritchard (2010: 81-2) does not clearly keep apart these two distinctions between explanatory understanding and explanatory knowledge, nor does he elaborate them; Hills (2010: 192-3) elaborates the first but does not recognize the second. 
correct belief about what the causes or reasons for something are, explanatory understanding additionally involves some grasp of these causes or reasons, including their relation to what they are causes or reasons for. If $q$ is the cause or reason why $\mathrm{p}$, then, when you know why $\mathrm{p}$, you correctly believe that $\mathrm{p}$ because q. When you understand why $\mathrm{p}$, you additionally have a grasp of how p causally or otherwise depends on q. Second, explanatory understanding requires a justification in a more demanding sense than explanatory knowledge does. When you know by testimony that $\mathrm{p}$ because $\mathrm{q}$, the only reason you may be able to provide for your belief is that a reliable expert has told you so. When you understand why $\mathrm{p}$, you have reflectively accessible grounds in favour of your explanation and are thus able to justify it by citing those reasons.

Talking of grasping causes or reasons, however, is only a metaphor. An obvious suggestion for spelling it out would be that grasping how $\mathrm{p}$ depends on $\mathrm{q}$ is equivalent to correctly believing that $\mathrm{p}$ because $\mathrm{q}$, combined with having a so-called "aha” feeling. Understanding is indeed often accompanied by such a feeling. But having an "aha” feeling is not necessary for explanatory understanding; you do not need to have a particular feeling when you finally come to understand why p. Having an "aha” feeling is not even sufficient for understanding why $\mathrm{p}$ if you know why $\mathrm{p}$. However strong your feeling of revelation may be when you know that $\mathrm{p}$ because $\mathrm{q}$, you do not understand why $\mathrm{p}$ if you are not able to explain how $\mathrm{p}$ depends on $\mathrm{q}$, and are thereby unable to say what would have been the case if factors cited in $q$ had been different in various ways.

The metaphor of grasping the causes or reasons why $\mathrm{p}$, then, is better spelled out in terms of having certain abilities that are not required for simply believing that the factors in question are the causes or reasons why p. Modifying a suggestion by Hills (2010: 194-5), let us say that if you understand why p (where q is why p), then you are (to some extent) able (i) to comprehend and render an explanation of $\mathrm{p}$ which shows (e.g. by means of a generalization) how $\mathrm{p}$ depends on $\mathrm{q}$, (ii) draw the conclusion that $\mathrm{p}$ (or that probably $\mathrm{p}$ ) from the information that $\mathrm{q}$, and (iii) for some $\mathrm{p}^{\star}$ and $\mathrm{q}^{\star}$, similar but not identical to $\mathrm{p}$ and $\mathrm{q}$, draw the conclusion that $\mathrm{p}^{\star}$ (or probably that $\mathrm{p}^{\star}$ ) from the counterfactual assumption that $\mathrm{q}^{\star}$, and, counterfactually assuming that $\mathrm{p}^{\star}$, explain it with the help of $\mathrm{q}^{\star}$. ${ }^{5}$ Knowledge also involves having certain abilities. Even knowing by testimony why the global mean temperature has increased requires the ability to quote the explanation given by

5 To demand, as Khalifa (2011a) does, that $q$ is the best available explanation for $p$ is too demanding in one respect and not demanding enough in another. A good explanation can provide some understanding of why $\mathrm{p}$, even if it is not the best explanation; but an understanding providing explanation must also show how p depends on the factors specified in q. As a result, understanding why $\mathrm{p}$ cannot even be identified with knowing that $\mathrm{q}$ is the best explanation for $\mathrm{p}$. 
the scientist. However, since you can know why p without having all of the abilities (i)-(iii), understanding why $\mathrm{p}$ is not the same as knowing why $\mathrm{p}$.

Consider a possible objection. In contrast to propositional knowledge, explanatory knowledge is gradual. It hardly makes sense to say that I know that it is raining better than you do; but it certainly makes sense to say that your knowledge why the global mean temperature has increased is better than mine. Minimal knowledge why $\mathrm{p}$ may be equivalent to knowing that $\mathrm{p}$ because $\mathrm{q}$; but good (or deep or comprehensive) knowledge why $\mathrm{p}$ involves knowing each of a whole set of true propositions, including propositions about how $\mathrm{p}$ depends on $\mathrm{q}$ and that if $\mathrm{q}^{\star}$ rather than $\mathrm{q}$ were true, then $\mathrm{p}^{\star}$ rather than $\mathrm{p}$ would be true. In the modified testimony case above, you have minimal knowledge why $\mathrm{p}$ without understanding why $\mathrm{p}$; but understanding why $\mathrm{p}$ is the same as good knowledge why $\mathrm{p}$. Furthermore, since explanatory understanding is also gradual, one might even claim that, in the testimony case, you have some minimal understanding why $\mathrm{p}$, and that minimal understanding and minimal knowledge why $\mathrm{p}$ are equivalent, as are good understanding and good knowledge why $\mathrm{p}$.

Notice that only the bolder claim at the end of the objection contradicts the thesis I defend in this section, namely that it is possible to know why $\mathrm{p}$ without understanding why p. So let me address it first. The modified testimony case suggests that even minimal explanatory understanding involves some grasp of how p depends on q, and, hence, involves possessing to some extent the abilities (i) to (iii). This rather demanding concept of understanding sensibly complements our concept of knowledge, which does not require having all of these abilities. You can know that the global temperature has increased because of increasing concentrations of greenhouse gases, but be unable to explain by means of a generalization how global warming depends on greenhouse gas concentrations and thus be unable to say what would have been the case if these concentrations did increase to a greater or lesser extent. You may even be unable to infer in some substantial sense that the global mean temperature has increased from the information that greenhouse gas concentrations have increased if this involves going through an argument which connects greenhouse gas concentrations and global warming by a generalization stating how the latter depends on the former. As a result, you can have minimal explanatory knowledge without minimal explanatory understanding. This suffices to defend my thesis. Moreover, good explanatory understanding may involve further abilities that are not required for good explanatory knowledge. A good understanding why the global mean temperature has increased may, for example, - like the objectual understanding of global warming (see Sect. 3) involve being able to develop emission scenarios and use them in order to predict future concentrations of greenhouse gases. If so, then you can have good explanatory knowledge without good explanatory understanding. 
According to the weaker claim in the objection, explanatory understanding is identical with good explanatory knowledge. This claim allows that explanatory understanding is not the same as minimal explanatory knowledge, since it involves the abilities (i) to (iii), but it objects that having these abilities is simply to have further knowledge, such as knowledge how $\mathrm{p}$ depends on $\mathrm{q}$, and that if $\mathrm{q}^{\star}$ rather than $q$ were true then $p^{\star}$ rather than $p$ would be true. Understanding why $p$ would then be a combination of minimal knowledge why $\mathrm{p}$ and some further knowledge. However, having these abilities is not the same as having extra pieces of knowledge, since you might have the further knowledge without being able to apply it to new situations nor being able to judge all kinds of counterfactual cases with its help (cf. Hills 2010: 195-6). If so, then you can have good explanatory knowledge without even minimal explanatory understanding. Of course, the objection might simply claim that good explanatory knowledge involves the abilities (i) to (iii) without trying to reduce them to further pieces of knowledge. If so, then having good explanatory knowledge is indeed sufficient for having explanatory understanding, but it is still not necessary for it - or so I argue in my next section.

\subsection{Understanding without knowledge}

Pritchard and Hills argue that cases involving epistemic luck show that it is possible to understand why p even while failing to know why $\mathrm{p}$ (Pritchard 2010: 78-9; Hills 2010: 106). If they are right, explanatory understanding is not even a form of explanatory knowledge.

Consider a case of what Pritchard calls "environmental epistemic luck", where the luckiness of one's true belief is entirely due to the fact that one is in an epistemically unfriendly environment. Suppose you study a reliable book and thereby acquire some understanding why the global mean temperature has increased. Suppose further that all other books about global warming are very unreliable but superficially just as scholarly, so that it is only by chance that you have chosen the reliable one. The epistemic luck involved in this case is usually taken as preventing you from knowing, since you could easily have bought an unreliable book and been given a false explanation; and, according to a widespread view, when one has knowledge, one's true belief could not easily have been false. However, the epistemic luck involved here does not undermine your understanding. After all, your explanation is correct, you do supposedly have some grasp of how global warming depends on increasing concentrations of greenhouse gases and possess some reasons for accepting the explanation provided, thus possessing the requisite explanatory and justificatory abilities (to 
some extent). This would still be the case if your own book was based on some inventive guesswork and thus very unreliable, but its explanation was, as a matter of luck, correct. The luck in this second case is what Pritchard calls "standard Gettier-style epistemic luck", that "intervenes' between the agent and the fact, albeit in such a way that the agent's belief is true nonetheless" (Pritchard 2010: 36). Hence I am inclined to claim, against Pritchard and with Hills (2010: 196, fn. 13), that explanatory understanding is also compatible with this second kind of epistemic luck. If this is right, then it becomes even clearer that one can understand why $\mathrm{p}$ without knowing why $\mathrm{p}$. While some have questioned whether knowledge is really incompatible with environmental epistemic luck (e.g. Grimm 2006: 527-9), it is widely accepted that it is incompatible with standard Gettierstyle epistemic luck.

Further support for the claim that explanatory understanding is compatible with both types of epistemic luck comes from a consideration by Kvanvig. He suggests that understanding has a different relationship to epistemic luck than knowledge due to a difference in focus (Kvanvig 2003: 197; 2009a: 97). When we think about understanding, we focus on grasping explanatory connections, and thus, we may add, on possessing certain abilities. When we think about knowledge, we focus on believing a proposition that could not easily have been false, and thus on non-accidentality. Hence, having acquired the belief in a lucky way does undermine explanatory knowledge, but having acquired the abilities in a lucky way does not undermine explanatory understanding. In this respect, understanding-why is like knowing-how, which is also compatible with epistemic luck. When we consider whether someone has know-how, we focus exclusively on whether he in fact has the ability in question, not on how he acquired it.

In Section 2.1 I argued that explanatory understanding requires grasping explanatory connections and having good reflectively accessible grounds supporting one's explanation. Both requirements are epistemically internal, since the facts which determine that the understanding person satisfies these requirements are accessible to that person. But explanatory understanding cannot be construed along purely internalistic lines. In order to understand why $\mathrm{p}$, one's explanation must answer to the facts. Like knowledge, understanding is therefore usually considered factive (Grimm 2006: 518; Pritchard 2010: 75-6; Hills 2010: 190; Khalifa 2011a: 95). However, whether it is indeed factive depends on how factivity is defined. If it turns out that understanding is not always factive, this would constitute a further reason why it is not even a form of knowledge.

According to Hills, explanatory understanding is factive iff you cannot understand why p if "p" is false (Hills 2010: 190). Understanding may indeed be factive in this sense: You cannot understand why the global temperature has increased if it has not increased. But the condition is too weak. Consider the factivity of knowl- 
edge that follows from the truth condition. You know why $\mathrm{p}$ if you know that $\mathrm{p}$ because q; this implies that " $p$ because q" is true. Hence, explanatory understanding seems to be factive iff you cannot understand why $p$, where you treat $q$ as the cause or reason why $p$, but either " $p$ " or " $q$ " is not true, or $q$ is not why $p$. However, understanding is not always factive in this sense, since scientific explanations often make use of idealizations. The ideal gas law, for instance, explains the behaviour of actual gases by describing the behaviour of a gas composed of perfectly elastic and perfectly spherical point masses that exhibit no mutual attraction. Such a gas cannot exist. Nonetheless, in circumstances where the divergence from the ideal is negligible (roughly, in cases of monoatomic gases at a high temperature and low pressure), the behaviour of actual gases is explained by reference to the idealization (Elgin 2007: 38). We can only acknowledge that such explanations provide some explanatory understanding if we admit that it is not always factive. Non-factive cases are further cases of understanding why $\mathrm{p}$ without knowledge why $p$, since you cannot know why $p$ if " $p$ because $q$ " is not (strictly) true.

Understanding why $\mathrm{p}$ involves a whole set of beliefs which constitute one's explanation. Besides the belief that $p$ because $q$ it involves beliefs regarding how $p$ depends on $q$ and that if $q^{\star}$ rather than $q$ were true, then $p^{\star}$ rather than $p$ would be true. The suggested factivity condition does not determine whether all these further beliefs must be true for explanatory understanding to be factive. This leads me to objectual understanding, the non-factivity of which I will discuss in some detail.

\section{Objectual understanding}

Does objectual understanding somehow reduce to explanatory understanding? This is the first question I have to address (Sect. 3.1). I then turn to the relation between objectual understanding and knowledge. Again, cases of knowledge without objectual understanding show that they are not equivalent (Sect. 3.2); cases of objectual understanding without knowledge show that the first is not even a form of the second (Sect. 3.3).

\subsection{Objectual and explanatory understanding}

Understanding a subject matter involves more than understanding why some fact involved in it obtains. Besides understanding why it occurs, understanding global warming involves, for instance, understanding what effects (on natural and social 
systems) it will have, how it is linked to human activities (such as burning fossil fuels and deforestation) and related phenomena (such as the destruction of stratospheric ozone and global dimming), how far greenhouse gas emissions and, as a result, temperatures are likely to rise in the future, and how the changes will vary over the globe. A broader understanding of global warming may even involve instrumental and moral understanding, such as understanding the (dis-)advantages of different responses to climate change (such as mitigation, adaptation and geo-engineering), and what a just distribution of emission rights amounts to. Much of the involved interrogative understanding may, on closer inspection, be explanatory understanding; understanding how global warming is linked to human activities, for example, may require an explanation of why its rate is increased by these activities. This raises the question whether we can reduce objectual understanding of a subject matter to explanatory understanding by conceiving it as understanding why some significant subset of facts or events concerning that subject matter obtained or occurred (as suggested by Khalifa 2011b).

Such a reduction does not seem to be feasible, for two reasons. First, even if all the involved interrogative understanding turned out to be explanatory understanding, having the explanatory understanding would not be sufficient for having objectual understanding. This additionally requires some awareness of how the different explanations fit into, contribute to, and are justified by reference to the more comprehensive understanding in which they are embedded. Second, having explanatory understanding is not even always necessary for having some objectual understanding, since it is possible to understand a subject matter by means of a theory that is not explanatory, at least to some extent. Eighteenthcentury biology, conceived of as a pure science of classification with no interest in explanation but with rigorous criteria of success (Gijsbers 2012), seems to provide some understanding of the animal kingdom since its classifications reveal significant similarities and allow successful predictions (e.g. about whether an animal of a hitherto unknown species is warm- or cold-blooded). However, this understanding cannot be formulated as understanding why something is the case (e.g. why some organism has a certain feature or why animals of a certain species exist). Of course, evolutionary theory has greatly advanced our understanding of the animal kingdom by providing us with explanations and improving our classifications. But if classificatory biology gives us at least some understanding, then understanding without explanation is possible. ${ }^{6}$

6 This example is due to Gijsbers (2012); further cases of understanding without explanation have been suggested by Lipton (2009) and critically discussed by Khalifa (2013). 
Typical cases of objectual understanding, however, contain explanatory understanding. Compared with a single instance of explanatory understanding, objectual understanding of a subject matter involves grasping more dependence (and similarity) relations in and by means of a more comprehensive body of information. The dependence relations can be of various sorts, including relations between parts or aspects of the subject matter (such as causal, probabilistic, mereological, supervenience and teleological relations) as well as relations between elements of the body of information (such as logical, conceptual and explanatory relations). In our example, this body of information is a full-fledged theory of global warming or even a complex of theories from different disciplines, such as climate science, economics and moral philosophy. Again, grasping manifests itself in certain abilities. Understanding global warming involves more of the same abilities as does understanding its causes: being able to comprehend and render explanations for a range of facts, draw conclusions from a variety of information, and judge counterfactual cases with respect to a web of explanations. Whether it also involves additional abilities depends also on whether or not the further interrogative understanding turns out to be explanatory understanding. Candidates for additional abilities would be, for example, being able to develop emission scenarios, to use them in order to predict future concentrations of greenhouse gases, assess uncertainties in climate model projections and evaluate rival responses to climate change.

\subsection{Knowledge without understanding}

Objectual understanding is not identical with knowledge since for each type there are cases in which one has knowledge but no objectual understanding. It follows from what has already been said that you can know that and even why a fact involved in a subject matter S obtains without understanding S. You can even know all important facts involved in S without understanding S. This is the case if you know these facts but fail to know how they are related - if, for instance, in addition to other facts, you know that the global mean temperature has increased and that concentrations of greenhouse gases have increased, but do not know that the second fact is the main cause for the first and thus explains it.

It is less clear whether you can know a subject matter $\mathrm{S}$ without understanding S. After all, as well as knowing the important facts involved in S, knowing S involves knowing how they are related. According to Brogaard (2005), this is also what distinguishes understanding S from simply knowing the facts involved in S. Hence, she identifies understanding $S$ with knowing $S$. However, the above discussion suggests that you can even know $\mathrm{S}$ without understanding $\mathrm{S}$. This is 
the case if you know the important facts involved in S and how they are related but fail to grasp the relations between them, and thus do not have the requisite explanatory abilities. ${ }^{7}$

\subsection{Understanding without knowledge}

Objectual understanding is not even a form of knowledge, since for each type there are cases in which one has objectual understanding but not knowledge. If environmental and standard Gettier-style epistemic luck do not undermine your understanding of the causes of global warming, then they do not undermine your understanding of global warming either. But they prevent you not only from knowing that and why the global mean temperature has increased, but also from having objectual knowledge of global warming. The reason is that we are rightly inclined to explain knowledge of $S$ in terms of knowledge of the facts involved in S. Perhaps we can fully explain knowing $S$ in terms of knowing facts; but we should at least claim that knowing $S$ involves knowing a number of facts constituting S. Hence, if epistemic luck prevents you from knowing that and why some fact involved in S obtains, it also prevents you from knowing S. Thinking otherwise would separate the different types of knowledge too much. The idea behind this argument is that we should not pull objectual knowledge so far apart from propositional and explanatory knowledge that we allow that epistemic luck prevents one from having the last two types of knowledge but not from having objectual knowledge (Kvanvig 2009a: 100; cf. Kvanvig 2003: 197).

Cases of environmental and of standard Gettier-style epistemic luck are already rare with respect to individual beliefs; and they are very unlikely with respect to theories about such complex phenomena as global warming. It is very unlikely that a book that is the result of some inventive guesswork should provide an entirely correct account of global warming; or that, while your book about global warming is reliable, all other books on the subject are very unreliable but superficially just as scholarly as yours. This is one reason why intuitions about whether we have understanding or knowledge in such cases vary strongly. Nonfactive cases of objectual understanding are quite frequent and less ambiguous.

Under what conditions should objectual understanding be considered factive? According to one obvious suggestion, understanding a subject matter S by

7 Following Kvanvig's terminology, Brogaard (2005) formulates her distinction between knowing the facts involved in S and knowing or understanding S in terms of "grasping" explanatory and other dependence relations. But according to her, grasping explanatory connections between two facts boils down to correctly believing or knowing that one is the cause or reason of the other. 
means of an account or theory $\mathrm{T}$ is factive iff all propositions that constitute $\mathrm{T}$ are true. However, even supporters of the factivity thesis acknowledge that a few peripheral falsehoods may degrade one's understanding of a subject matter but will certainly not undermine it completely. Thus the conditions for objectual understanding to be factive should be weaker: Understanding a subject matter $\mathrm{S}$ by means of an account or a theory $\mathrm{T}$ is factive iff most of the propositions and all of the central propositions that constitute T are true (Kvanvig 2003: 201-2). This is vague in two respects. The conditions determine neither how many false propositions can be tolerated without undermining the understanding, nor which propositions count as central and which as peripheral. This vagueness gives ample scope to rescue the factivity of understanding. Nonetheless, as Elgin (2007: 36-9) has argued, there are two kinds of clear cases in which objectual understanding is not factive. Both assume that we should construe our concept of understanding in such a way that we can acknowledge that science admits at least some understanding of the phenomena it is concerned with. In what follows, I reconstruct Elgin's arguments and defend them against objections raised by Kvanvig.

Firstly, understanding is more gradual than supporters of the factivity thesis think, since even falsehoods that are rather central sometimes only decrease the degree of understanding but do not destroy it completely. ${ }^{8}$ In everyday learning processes as well as in scientific education, we work from characterizations that are strictly false but which properly direct us towards the phenomena to beliefs that are closer to the truth. Even if the development results in true beliefs, an earlier step also displays at least some understanding. The same pattern is shown by sequences of scientific theories. Think of a Ptolemaic, a Copernican and a contemporary theory of the motion of the planets. Despite the fact that Copernicus falsely assumed that the Earth travels around the sun in a circular orbit, the theory it belongs to constitutes a major advance in understanding compared to the Ptolemaic theory. We can only acknowledge that Copernicus has at least some understanding of the motion of the planets if we admit that even some rather central falsehoods lower the degree of understanding but do not undermine it completely, if they are in the right neighbourhood. Moreover, even current scientific theories do not largely consist of truths with a few relatively insignificant

8 Kvanvig maintains that where you have some understanding of a subject matter, even if some propositions within your account are false, the false propositions are not part of your understanding (Kvanvig 2003: 201-2). However, in the given case, the falsehoods are rather central. This means that they bear evidential, explanatory and other dependence relations to other propositions within your account. As a result, it is difficult to see in what sense we can talk about the understanding one has of a subject matter once one has "subtracted" these falsehoods from the account that constitutes one's understanding (cf. Riggs 2009: 335). 
falsehoods at the periphery. Hence, we can only acknowledge that current science exhibits at least some understanding of the phenomena it is concerned with if we allow that understanding is not always factive.

Kvanvig objects that in such cases we use "understanding" in an honorific sense, just as we use "knowledge" when we speak of "the current state of scientific knowledge", while conceding that some part of it may be false. But honorific usages of epistemic terms, as Kvanvig maintains, belong to the pragmatics rather than to the semantics of epistemic terminology. Just as honorific uses of "knowledge" have no bearing on what knowledge is, honorific uses of "understanding" have no bearing on what understanding is (Kvanvig 2009b: 341-2). However, this analogy does not seem to be compelling. In ordinary usage, we retract a claim to know a proposition if we discover that it is false. Hence, it is reasonable to construe propositional, and, by extension, objectual knowledge as factive. But our ordinary usage of "understanding" as applied to a subject matter is more flexible. We readily agree that Copernicus did not know that the Earth's orbit is circular, but it seems inappropriate to deny him any understanding of the motion of the planets. We typically acknowledge that people can have some understanding even if some rather central propositions of their account diverge somewhat from the truth. Hence, it is reasonable to construe understanding (of some subject matter) as non-factive.

Secondly, as already mentioned, science often makes use of idealizations. Physicists purport to understand the behaviour of actual gases by reference to the ideal gas law; environmental scientists purport to have some understanding of global warming by reference to simplified climate models. The idealizations are, strictly speaking, false, but they can neither be eliminated from scientific theories nor banished to their periphery. Hence, we can only acknowledge that science exhibits an understanding of the phenomena it is concerned with if we admit that idealizations do not destroy it. Some approximations are accepted simply because they are the best that science can currently do, others are preferable to the complicated truth they approximate; hence, in contrast to the falsehoods mentioned in the first cases, they do not even lower the degree of understanding. This implies that truth is only one of many epistemic desiderata which understanding should realise, and that it can be overridden by others, such as generality, simplicity, parsimony, explanatory power and applicability. ${ }^{9}$

9 The relative weights of these epistemic desiderata also depend on pragmatic considerations. Applicability, for instance, is more important than parsimony, if we are striving for an account that can directly be utilized in practice. 
Kvanvig objects that idealizations will not imply non-factivity once we appreciate that the object of understanding is not simply the model itself but involves a relationship between model and reality, including information about the extent to which the model is an idealization and what aspects of reality it is intended to shed light on (Kvanvig 2009b: 342-3; cf. Greco 2012: 126-7). However, the object of understanding is neither the model nor the model and its relation to reality, but rather the phenomenon in the world. Such an understanding presupposes an understanding of the model in question combined with an awareness that it is an idealization. But it does not always seem to include knowledge of precisely how the model diverges from reality. Otherwise it would be difficult to see what the point of the idealization is. Environmental scientists do not know exactly how their climate models diverge from reality; but this does not completely undermine their understanding of global warming.

In a case of non-factive understanding, some of the central propositions constituting your account of S may be false; if so, you may have some understanding of S without knowing all central facts involved in S, and, indeed, without knowing S. Here is an argument why - which is, again, based on the idea that the different types of knowledge should not be separated from each other too much. Objectual understanding is not factive; propositional knowledge is factive. If one takes some types of knowledge as factive and others as not factive, this separates them too much. Hence, objectual knowledge should be considered factive. But then there are further cases of objectual understanding that do not entail objectual knowledge.

\section{Characteristics of understanding}

As a result of my discussion, important characteristics of explanatory and objectual understanding have emerged which distinguish them from different types of knowledge.

(a) Explanatory and objectual understanding are gradual. They can vary in breadth, depth and accuracy (and perhaps in other ways as well). The scientist's understanding of global warming and its causes is broader and deeper than your understanding since she grasps more dependence relations and more basic ones in and by means of a more comprehensive body of information. Her understanding is more accurate since most of her beliefs are true or at least close to the truth, while some of your beliefs are still more or less the crude characterizations of a novice. In contrast, propositional and minimal explanatory knowledge (i.e. knowledge that $\mathrm{p}$ because $\mathrm{q}$ ) are not gradual at all, good explanatory and objectual knowledge are not gradual to the same extension in the third dimen- 
sion; because of the factivity condition, most of the propositions and all central propositions of the account must be true.

(b) Explanatory and objectual understanding are no species of belief, since they involve a whole set of beliefs; they are not even fully explicable as collections of beliefs, since, beside beliefs, they involve grasping dependence relations and thus call upon certain abilities. Furthermore, understanding need not be couched in true beliefs; it might equally well be located in apt categories and effective non-verbal symbols, such as diagrams, graphs and three-dimensional models. In contrast, propositional and minimal explanatory knowledge are species of belief; good explanatory and objectual knowledge can be explained as collections of beliefs.

(c) Explanatory and objectual understanding are not always factive. An explanation of why $\mathrm{p}$ and an account of a subject matter $\mathrm{S}$ can be more or less accurate and may essentially include idealizations. In both cases, the vehicle involves propositions that are not strictly true, and some of them may even be central to the explanation or account. In contrast, knowledge is undermined by (non-peripheral) falsehoods. Knowing that p implies that "p" is true, knowing why $p$ implies that " $p$ because $q$ " is true, and knowing $S$ implies that most of the propositions and all the central propositions of the account of $S$ are true. However, understanding is also some sort of cognitive success. Hence, even though it is not factive, it has to answer to the facts. As a consequence, understanding is not transparent: Thinking that one understands why $\mathrm{p}$ or a subject matter $\mathrm{S}$ does not entail that one understands why $\mathrm{p}$ or $\mathrm{S}$.

(d) Explanatory and objectual understanding have an internalistic dimension. Besides grasping dependence relations and the abilities involved in it, they require good reflectively accessible grounds in support of one's explanation or account, and thus the ability to justify it. Both requirements are internal to cognition because they do not depend on factors outside the control of the person who possesses the understanding. In contrast, propositional and explanatory knowledge may, by epistemically externalist lights at least, sometimes be opaque to the subject.

(e) Explanatory and objectual understanding are related to a plurality of epistemic desiderata. They demand an epistemic value pluralism, according to which truth is only one of many epistemic desiderata and can be overridden by others. Categories and non-verbal symbols are epistemically more or less appropriate, even though they are neither true nor false; idealizations can be epistemically valuable although they are known to be false. In contrast, propositional knowledge admits of an account that takes truth to be the sole or at least the highest epistemic desideratum. If such an epistemic value monism acknowledges other epistemic desiderata besides truth, then it claims that they are desiderata only insofar as they facilitate our reaching the truth (cf. Brogaard 2009: 284). 
(f) Explanatory and objectual understanding are compatible with epistemic luck. They are neither undermined by environmental epistemic luck nor by standard Gettier-style epistemic luck. The reason for this is that what is distinctive about understanding, once the answering-the-facts requirement is satisfied, is internal to cognition: the grasping of connections and justifying of the commitments that undergird one's understanding and thus the possessing of certain abilities. Since possessing the abilities is not undermined by epistemic luck, understanding is not undermined either. In contrast, knowledge is usually considered to be incompatible with epistemic luck. The reason is that what is distinctive about knowledge, once the truth condition (and, maybe, a justification condition) is satisfied, is external to cognition: the non-accidentality of the connection between mind and world and thus that one's true (and justified) belief could not have easily been false. Since your beliefs could have easily been false in cases of epistemic luck, the luck prevents you from knowing (cf. Kvanvig 2003: 197).

These six characteristics do not directly lead to definitions of the concepts of explanatory and of objectual understanding, but they provide guidelines for such definitions. According to (a), the definiens and the definiendum have to be construed as gradual. According to (b), the definiendum has to include a grasping condition that should be spelled out in terms of possessing certain abilities. I have specified the abilities required for explanatory understanding, and indicated by way of an example what kind of abilities objectual understanding may additionally involve. In the case of symbolic understanding, one can grasp explanatory and other dependence relations within an explanation or account without committing oneself to them. However, factual understanding of something by means of the explanation or account presupposes that one commits oneself to the explanation or account, including its non-propositional elements (see Sect. 1). Hence, the grasping condition has to be supplemented by a commitment condition, which corresponds to the belief condition for propositional knowledge. According to (c), the definiendum must include an answering-the-facts condition that corresponds to the truth condition for knowledge; according to (d) it must include a justification condition that must be construed along epistemically internalistic lines. While justification in connection with knowledge is conceived of as truth-conducive, understanding according to (e) requires a justification that is related to a plurality of epistemic desiderata. However, (f) implies that the definiendum does not need a further external anti-luck condition besides the epistemically internal justification condition. 


\section{Propositional understanding}

I have argued, first, that neither explanatory understanding nor objectual understanding are forms of knowledge. On the one hand, it is possible to have knowledge without having explanatory or objectual understanding, since in contrast to knowledge they require the grasping of dependence relations in a way that involves having certain abilities as well as reflectively accessible grounds in support of one's explanation or account. On the other hand, it is possible to have explanatory or objectual understanding without having knowledge, since, in contrast to knowledge, they are not always factive and are compatible with epistemic luck. Second, I have argued that objectual understanding is not reducible to explanatory understanding. Having explanatory understanding is not sufficient for objectual understanding since this additionally involves some awareness of how the explanatory understanding fits into and is justified by reference to the more comprehensive understanding in which it is embedded. Having explanatory understanding is not always necessary for having objectual understanding since one can have some objectual understanding by means of a theory that is not explanatory. But is explanatory understanding not a form of propositional understanding? And, if it is, would this not pave the way for reducing explanatory understanding to propositional knowledge nonetheless? These are the questions I address in this final section.

The reduction starts from two widespread claims. One takes explanatory understanding to be a form of propositional understanding; the other identifies propositional understanding (excluding hedging and moderating usages) with propositional knowledge:

(11) Understanding why $\mathrm{p}$ is equivalent to understanding that $\mathrm{q}$ is a correct answer to the why-question (cf. Kvanvig 2003: 189-90). ${ }^{10}$

(12) Understanding that $\mathrm{p}$ is equivalent to knowing that $\mathrm{p}$ (cf. Elgin 2007: 34; Grimm 2011: 85).

Since we can substitute "that p" in (12) by "that q is a correct answer to the whyquestion" from (11), (11) and (12) together imply:

(13) Understanding why $p$ is equivalent to knowing that $q$ is a correct answer to the why-question.

10 A more orthodox formulation is: (11*) Understanding why $\mathrm{p}$ is equivalent to understanding that q, where q is a correct answer to the why-question. However, $\left(11^{\star}\right)$ seems obviously false. You do not understand why $\mathrm{p}$ if you understand that $\mathrm{q}$, but fail to see that $\mathrm{q}$ is a correct answer to the question why $\mathrm{p}$ (cf. Brogaard 2005). 
The reduction claim (13) is attractive since it suggests a possibility of explaining the elusive notion of explanatory understanding in terms of the much better understood notion of propositional knowledge.

However, if my argument is sound and explanatory understanding is neither identical with nor a form of knowledge, then (13) fails. You can know that $q$ is a correct answer to the question why $\mathrm{p}$ without understanding why $\mathrm{p}$ if you fail to have the requisite explanatory and justificatory abilities. You can even understand why $\mathrm{p}$ without knowing $\mathrm{q}$ as a correct answer to the question why $\mathrm{p}$, for example if q involves some idealization. If (13) fails, then either (11) or (12) or both of them have to be given up.

I think (11) should be rejected, since reducing explanatory understanding to propositional understanding faces a dilemma. Either the propositional understanding is construed in such a way that its content is exhausted by a proposition concerning what the causes or reasons for $\mathrm{p}$ are, or it is construed in a much more demanding way. If the content of the propositional understanding is exhausted by a proposition concerning what the causes or reasons for $\mathrm{p}$ are, then the proposed reduction is impossible. Besides knowing a proposition to the effect that $p$ because $q$, understanding why $\mathrm{p}$ additionally involves some grasp of how $\mathrm{p}$ depends on the causes or reasons specified in $q$ and thus on the explanatory abilities (i)-(iii), as specified in Section 2.1. This problem could be solved by construing propositional understanding very demandingly so that it involves a conjunctive proposition, including propositions about how $\mathrm{p}$ depends on $\mathrm{q}$, and that if $\mathrm{q}^{\star}$ rather than $\mathrm{q}$ were true then $\mathrm{p}^{\star}$ rather than $\mathrm{p}$ would be true, as well as the requisite explanatory and justificatory abilities. If propositional understanding is construed in a such a demanding way, then the proposed reduction is unhelpful. Propositional understanding is then no better understood than explanatory understanding; so reducing the second to the first does not help us. Thus, (11) should be rejected, since reducing explanatory to propositional understanding is either impossible or unhelpful.

Giving up (11) makes it possible to stick to (12) and to identify propositional understanding with propositional knowledge, a claim that is accepted by almost all participants in the debate on understanding. As a result, there is no need for an extra definition of the concept of propositional understanding. We have only to search for definitions of the concepts of explanatory understanding and of objectual understanding. One of the aims of this paper was to specify the conditions any such definition should include. ${ }^{11}$

11 I would like to thank audiences in Kirchberg, Dresden and Zurich, and in particular Monika Betzler, Georg Brun, Gertrude Hirsch Hadorn, Peter Schaber, Pedro Schmechtig as well an 


\section{References}

Brogaard, B. 2005: I know. Therefore, I understand. Unpublished typescript.

Brogaard, B. 2009: The Trivial Argument for Epistemic Value Pluralism, or, How I Learned to Stop

Caring about Truth. In: Haddock/Millar/Pritchard 2009: 284-305.

Cooper, N. 1994: Understanding. In: Proceedings of the Aristotelian Society, Suppl. 68, 1-26.

Elgin, C. Z. 1996: Considered Judgment. Princeton: Princeton University Press.

Elgin, C. Z. 2007: Understanding and the Facts. In: Philosophical Studies 132, 33-42.

Gijsbers, V. 2012: Understanding, Explanation, and Unification. In: Studies in the History and Philosophy of Science, http://dx.doi.org/10.1016/j.shpsa.2012.12.003.

Greco, J. 2012: Intellectual Virtues and Their Place in Philosophy. In: Jäger, C.; Löffler, W. (eds):

Epistemology: Contexts, Values, Disagreement. Frankfurt am Main: Ontos, 117-130.

Grimm, S. R. 2006: Is Understanding a Species of Knowledge? In: British Journal for the Philosophy of Science $57,515-535$.

Grimm, S. R. 2011: Understanding. In: Bernecker, S.; Pritchard, D. (eds): Routledge Companion to Epistemology. New York: Routledge, 84-94.

Haddock, A.; Millar, A.; Pritchard, D. (eds) 2009: Epistemic Value. Oxford: Oxford University Press.

Hills, A. 2010: The Beloved Self. Morality and the Challenge form Egoism. Oxford: Oxford University Press.

Khalifa, K. 2011a: Understanding, Knowledge, and Scientific Antirealism. In: Grazer Philosophische Studien 83, 93-112.

Khalifa, K. 2011b: Is Understanding Explanatory or Objectual? In: Synthese, doi 10.1007/ s11229-011-9886-8.

Khalifa, K. 2013: The Role of Explanation in Understanding. In: British Journal for the Philosophy of Science 64, 161-187.

Kvanvig, J. 2003: The Value of Knowledge and the Pursuit of Understanding. New York: Cambridge University Press.

Kvanvig, J. 2009a: The Value of Understanding. In: Haddock/Millar/Pritchard 2009: 95-111.

Kvanvig, J. 2009b: Response to Critics. In: Haddock/Millar/Pritchard 2009: 339-351.

Lipton, P. 2004: Inference to the Best Explanation. New York: Routledge.

Lipton, P. 2009: Understanding without Explanation. In: de Regt, H. W.; Leonelli, S.; Eigner, K. (eds): Scientific Understanding. Pittsburgh: University of Pittsburgh Press, 43-63.

Pritchard, D. 2010: Knowledge and Understanding. In: Pritchard, D.; Millar, A.; Haddock, A: The Nature and Value of Knowledge. Three Investigations. Oxford: Oxford University Press, 1-88.

Riggs, W. D. 2003: Understanding "Virtue" and the Virtue of Understanding. In DePaul, M.; Zagzebski, L. (eds): Intellectual Virtue. Oxford: Clarendon Press, 203-226.

Riggs, W. D. 2009: Understanding, Knowledge, and the Meno Requirement. In: Haddock/Millar/ Pritchard 2009: 331-338.

Salmon, W. 1993: The Value of Scientific Understanding. In: Philosophica 51, 9-19.

Woodward, J. 2003: Making Things Happen. A Theory of Causal Explanation. New York: Oxford University Press.

Zagzebski, L. 2001: Recovering Understanding. In: Steup, M. (ed.): Knowledge, Truth and Duty. New York: Oxford University Press, 235-251.

anonymous referee of Conceptus for critical comments on earlier versions of this paper. They have been very helpful. 